\title{
Implementing a HBIM approach to manage the translocation of heritage buildings
}

\section{Purpose}

The purpose of the paper is to present a study which exploited synergies between the fields of Heritage BIM, conservation and building translocation to develop a new approach to support a digitally enabled translocation process. The translocation (or relocation) of buildings or structures is a niche area of the construction sector and much of the significant work in this field has focused on the relocation of heritage buildings. However, hitherto there was a paucity of work integrating translocation with the process and technology of BIM.

\section{Design/Methodology/Approach}

The study employed a Constructive Research approach to analyse the phenomenon of heritage translocation. As part of this approach, semi structured interviews were undertaken with professionals engaged in heritage translocation projects within the UK and this was supported by a multi-faceted review of literature within the cross cutting themes of translocation and HBIM. Building on the results, a BIM enabled process was implemented to support the translocation of a $19^{\text {th }}$ Century timber framed building in the UK.

\section{Findings}

Following analysis of results of semi structured interviews, and supported by findings from prevailing literature in the field of translocation and HBIM, a HBIM for Translocation Conceptual Framework (TransHBIM) was developed. Building on the key constructs of the framework, a HBIM based workflow was implemented to develop a digitally enabled translocation process which provided a new approach to managing and documenting heritage translocation where disassembly and reconstruction is 
utilised. The workflow provided a more effective way of documenting individual elements of the building within a digital environment opening up potential for new simulation of the entire process.

\section{Originality/Value}

Current approaches to translocation involve manual methods of recording the building and cataloguing the key heritage elements for all aspects of the process. This new approach implements BIM technologies and processes along with the use of barcode or RFID tags to create a digital bridge between the physical elements of the building and the BIM database. This provides more accurate recording of the heritage and also opens up opportunities to support the process with additional digital simulation techniques enhancing the efficiency of the entire process.

Keywords: BIM, Conservation, 4D-BIM, HBIM, Heritage, Laser Scanning, Translocation 


\section{Introduction}

It has been suggested that the movement of a building should only be undertaken when all other avenues have been exhausted and the structure is in danger (Curtis, 1979). Historic buildings are particularly in danger as they often become symbols of the tangible cultural heritage of a place and so they are required to be retained from a wider historical perspective (Xu et al. 2014). The only option at this stage is to move the building to a more suitable location, ensuring its longevity (Peltola, 2008). The relocation, or translocation, of buildings can be undertaken using one of three methodologies; intact and as a complete structure, through partial disassembly or through complete disassembly and reconstruction (Curtis, 1979). There have been some notable and high-profile translocations of buildings and structures throughout history. Some short distance and complete structure translocations include the Empire theatre in New York, whereas the Abu Simbel temples in Egypt used the disassembly approach to relocate the structures a few hundred metres from their original site to protect them from rising water.

During a complete structure translocation, the process involves the entire structure being cut off (normally at the foundation) to become a free-standing entity and then moved as a single element (Podhalański \& Połtowicz 2019). One of the issues faced during this process is the integrity of the building and the structural performance. Often during a translocation of this nature, work is needed to design and develop movable structural underpinning systems which can carry uniform loads without compromising structural integrity of the building (Guo et al., 2013). The entire relocation approach is a high cost and often technically difficult operation. The alternate method of translocation involves (whole or partial) disassembly and reconstruction which is a more common 
method requiring limited specialist equipment and also providing the ability to remediate any structural issues during the process (Wesołowski, 2016).

With all heritage building translocation, a survey is undertaken to record the building in its existing state. Very often this is done as a visual inspection (Zhang et al., 2019) and can include the 'drawing up' of plans of the buildings in addition to recording of specific aspects using photography. Furthermore, the process of translocation is then planned and executed using traditional construction mechanisms. Hitherto, traditional means of undertaking the translocation process have involved traditional data capture through drawings/sketches, photographs and more manual measurement which have then fed into disassembly and reconstruction based on the knowledge of specialists. Furthermore, this approach has led to inaccurate time and cost estimates for the project (Kolakowski, 2015). The processes and technologies associated with Building Information Modelling (BIM) now provide an opportunity to transform these traditional approaches and provide more certainty through the capture, structuring and exploitation of digital data.

BIM has been defined as the use of computer based models to simulate the design, construction and operation of a building or asset, whereby the views and data derived from the model can be used to underpin processes at various stages of the building lifecycle (Barnes, 2019). To date, BIM is having a significant impact on all aspects of the built environment, and it is acknowledged that it brings together formalised processes and workflows along with a range of digital technologies, all underpinned by specific policies (Succar, 2009). The use of the digital data, integrated with the information rich 3D graphical models, starts early in the project development cycle 
(Mordue et al., 2015) . For standard construction projects, the model is continually updated throughout design and construction such that it can eventually become a rich source of digital data which can support the operation stage of a building as a facility management tool (Riaz et al., 2017) .

Heritage (or Historic) BIM (HBIM) is a specific domain within the BIM paradigm, which focuses on the application of BIM tools and techniques to heritage buildings. Predominantly, this focuses on digitally recording the tangible asset as a 3D computer model and it has been proposed that this approach has increased in parallel with the availability of access to laser scanning and photogrammetry tools (Dore et al., 2012; Laing et al., 2015; Apollonio et al., 2017). Dore et al., (2015) suggested that the 3D HBIM could be used for much more than pure visualisation of the building. This could include bringing together a range of disparate data sets that could be used to support the management of the building (Tommasi et al., 2016) or a range of more detailed analyses (Baik et al., 2015). Noting that in some translocation projects, a limited number of digital tools, such as laser scanning, have been implemented, a full BIM (process and technology) approach has not yet been applied. In addressing the paucity of knowledge in this field of translocation, a HBIM approach could be used to support disassembly and reconstruction.

Based on the contextual backdrop provided, the aim of this study was the development of a conceptual framework leading to the implementation of a HBIM based methodology for the translocation of heritage buildings. Specifically, the objectives of this work was to: 
- Critically evaluate research and practice in the field of translocation and examples of previous translocations to understand methodologies employed

- Analyse current and prevailing BIM processes and technologies, specifically related to HBIM which could impact on translocation activities

- Develop a conceptual framework for the use of HBIM for use in translocation of heritage buildings

- Implement the framework on a real-world translocation project to identify practical issues around HBIM for heritage translocation

\section{Research methodology}

The underpinning philosophy of this study is built on a Constructive Research (CR) approach. This particular approach was selected as it provides a means for solving problems faced in the real world by applying prior theoretical knowledge (Lukka, 2003). Furthermore it has been shown to be applicable to the management of projects in the construction domain (Oyegoke ,2011). The CR approach allows for the synergising of both theory and practical experience to develop a new construct or methodology (Oyegoke, 2011). One of the key benefits of CR is the ability to couple each stage with a set of research methods in the design of new processes, allowing for further appropriate methods to be employed during the development of the overall research (Lehtiranta et al., 2015). CR is undertaken in six distinct phases (Kasanen et al., 1993) and the relationship of these phases to this study and paper have been identified in Figure 1. The focus of this paper is to report on the development of the first four phases of the research approach, culminating the development of a HBIM for Translocation framework and the initial implementation on a test project. 


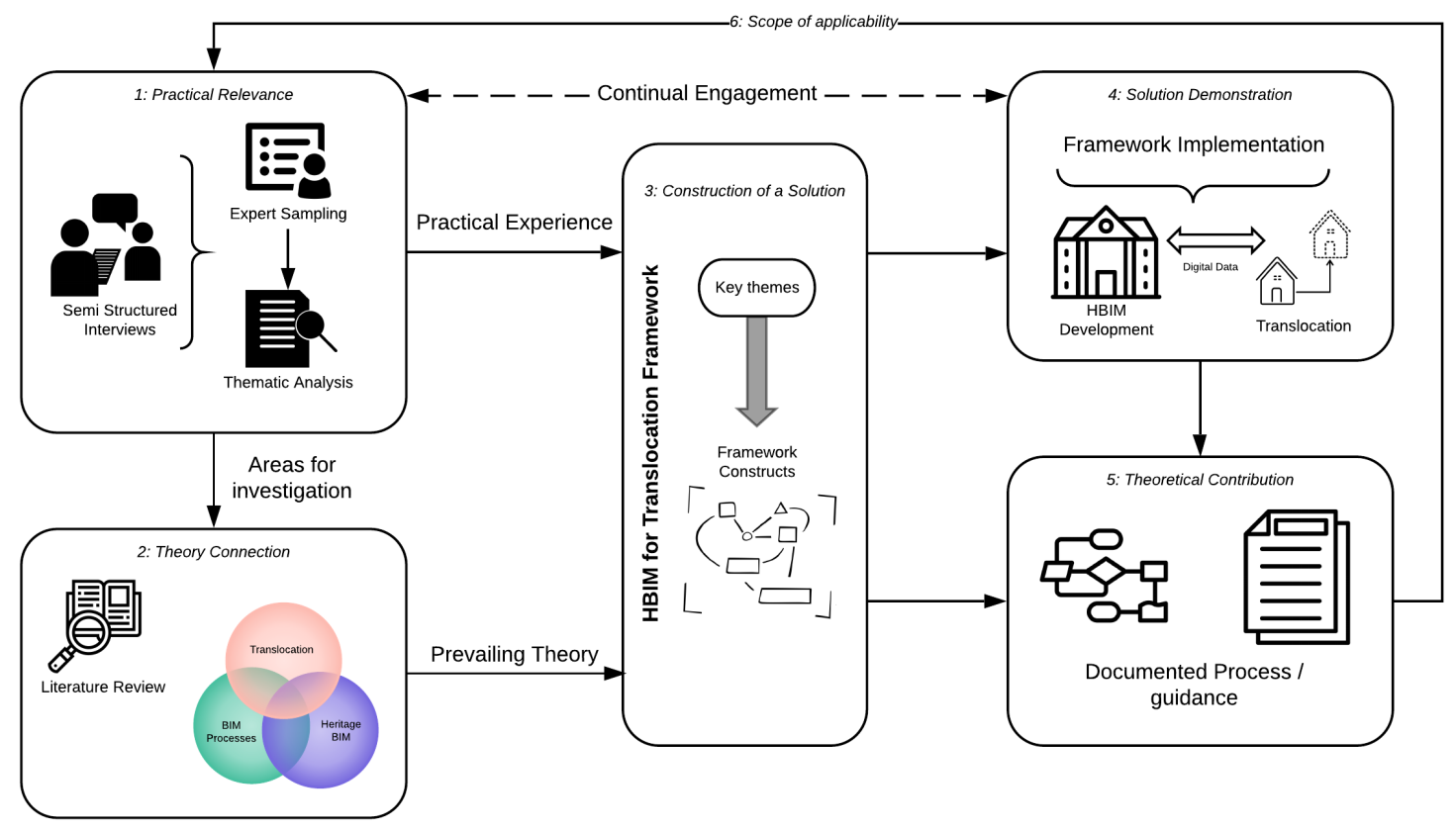

Figure 1: CR Approach for the study

(Derived from Kasanen et al., 1993; Oyegoke, 2011)

For the first three phases of the research, an inductive approach was adopted viewed through an interpretivist lens. The use of interpretivism underpinned the semi structured interviews with individuals who have previously been involved with the translocation of heritage buildings, providing a range of viewpoints from alternate perspectives thus identifying key issues (Saunders et al., 2016). Within a review of existing literature, this philosophy was deemed most appropriate as it allowed the examination of existing studies within the dual paradigms of translocation and HBIM and from here findings could inform the new direction purported in this paper (Schweber, 2015). Furthermore, this cross cutting review provided a deeper understanding of the complexity of each of the specific fields of translocation and HBIM, whilst also trying to elicit key findings which could be applied to the development of a new framework in a congruent manner. 


\section{Key issues from practical experience}

An initial identification of some key issues was undertaken through semi-structured interviews with six professionals who have experience of historic building translocation. In order to select the interview participants, a purposive sampling method was employed, specifically implementing the expert sampling approach. This method was utilised as it supported the first phase of the CR research approach but also it is noted as beneficial when eliciting knowledge about a specific field to identify potential areas of research (Etikan et al., 2016). Six professionals were selected which covered the range of stakeholders involved in specialist translocation projects (Table 1). As the nature of this topic is highly specific with a limited number of specialist professionals focusing on this niche area of construction, this smaller sample size spanned expertise across all of the stakeholders providing an evidence base for further development of the study (Etikan et al., 2016).

Table 1. Semi Structured interview participants

\begin{tabular}{|l|l|l|}
\hline Job Title & Stakeholder & Experience \\
\hline Head of Collections & Building Museum & 5 years \\
\hline Client-side project manager & Building Museum & 11 years \\
\hline Building Surveyor & Heritage Surveyors & $>20$ years \\
\hline Project Manager & Building Contractor & 15 years \\
\hline Architectural Designer & Project Architect / Museum & 16 years \\
\hline Curator & Building Museum & 6 Years \\
\hline
\end{tabular}

Within the interviews, issues explored included the planning process, physical translocation process including on site activities, the use of any digital technologies 
during translocation and issues of project/process management. Following collection of the data and transcription, a thematic analysis was undertaken to understand key issues relating to translocation projects (Figure 2). Initially 3 key themes were identified covering the historic context of the building, understanding the existing condition and recording of the building and finally the actual process of translocation. Underpinning each of these themes was the actual approach to translocation, i.e. complete relocation, disassembly/reconstruction or hybrid approaches.

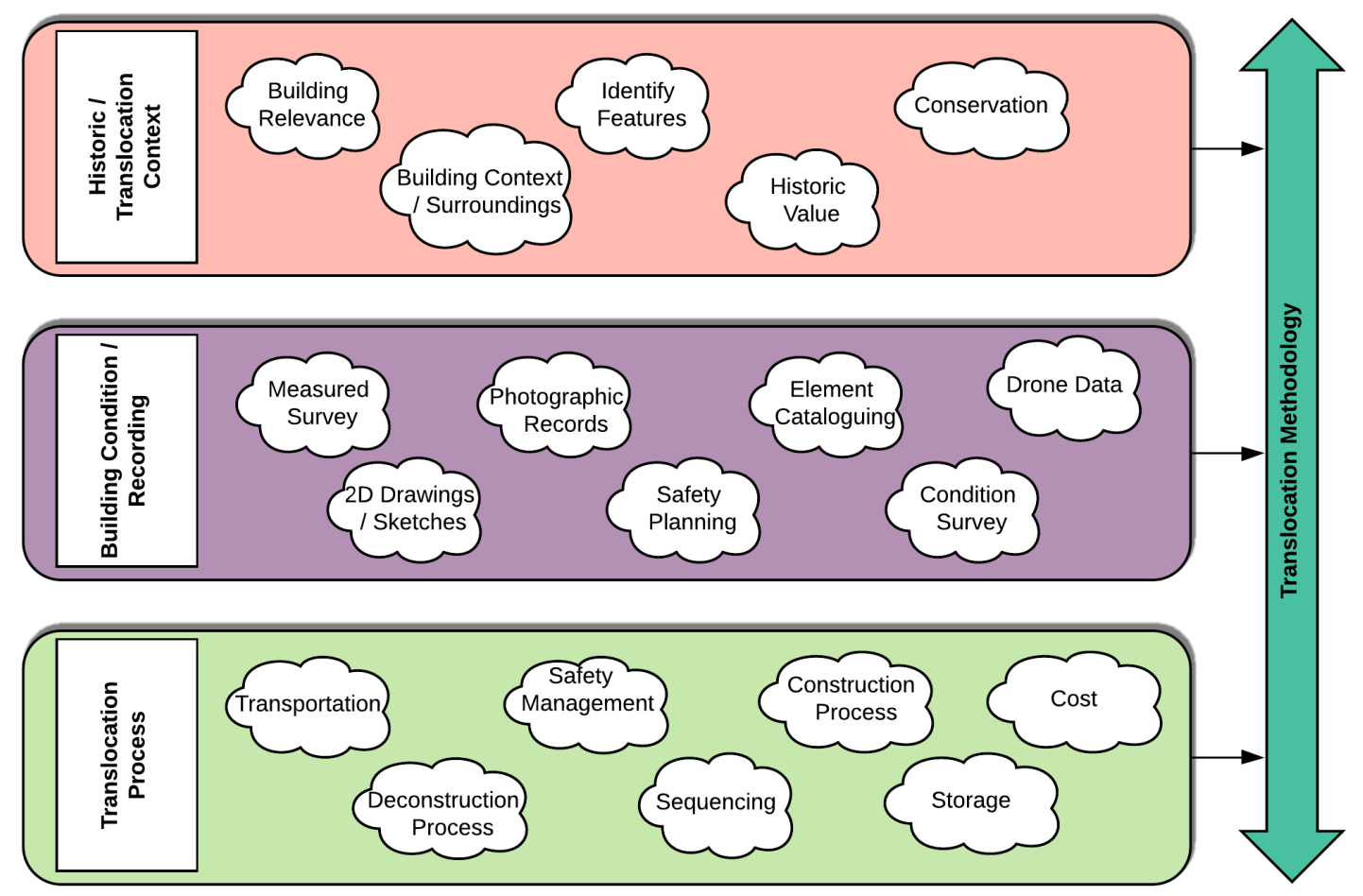

Figure 2: Thematic Analysis from Practical Experience

Within each of the main themes, sub-themes were identified, and these then helped to identify potential aspects of the translocation process which could be supported by BIM Processes and Technologies. Subsequently, the following review of literature seeks to identify prevailing knowledge which can be applied to historic translocation. This is categorised into translocation research, emerging HBIM developments and existing BIM processes which could be support translocation. 


\section{Literature Review}

The following review presents and analysis of current and emerging trends in the field of historic building translocation. This includes identifying the prevailing variant approaches to such as 'complete building translocation' and disassembly and reconstruction. By understanding the translocation, issues surrounding existing HBIM practices are discussed to understand how BIM technologies and processes can be aligned to translocation activities.

\section{Approaches to building translocation}

Very often, translocation is used as a form of preservation and this is particularly true for heritage buildings, although it is increasingly also being used for non-historic buildings (Wong, 2016). The movement of historic structures generally have a greater risk than the movement of non-historic as often the structural elements and the inherent materials are more fragile (Jackier, 2001).

The overall management of the translocation process is critical to the success. Undertaking a feasibility analysis of the move, whether this is a whole building or disassembly technique, is critical as this directly impacts time and cost of the overall project (Lu \& Wang, 2016). The issue of the cost of a translocation project is highlighted by Kolakowski (2015) noting that the cost of these ventures is often high and this can be impacted by a range of management based decisions/activities including time, risk, process, finance, logistics and human resource. Due to the complexities of the process, the estimation of the cost can also be challenging. 
The process of translocation can often lead to changes in the building as a form of adaptive reuse, and this can be because of certain elements being of unusable quality in the new construction (Yusran et al., 2019). It has been proposed that when a complete structure translocation is undertaken the original character is retained (Podhalański \& Połtowicz, 2019). However, there is the further issue of the translocation of the building, from its original geographic location, losing its sense of place (Yusran et al., 2019) or the 'Genius Loci'. This is due to the new location of the building not relating to the atmosphere of the original building surroundings (Tomaszek, 2020). The loss of context of the surroundings during a building translocation can remove elements of architectural perspective, however, it can also be true that where the building is not in danger then the removal from its original location could leave a void in the context of the original locale (Goblet, 2006). Since the 1877 Manifesto of the Society for the Protection of Ancient Buildings, the protection and conservation of buildings has been identified as critical to the preservation of cultural heritage. The subsequent Venice Charter of 1964 was adopted by the International Council on Monuments and Sites (ICOMOS) and paved the way for the adoption of the Burra Charter in 1979 developed by Australia ICOMOS. This seminal document provides guidance on best practice for managing heritage places and has seen ongoing updates in 1988, 1999 and 2013 (Australia ICOMOS, 2013). An underpinning philosophy of the charter, highlights that the physical location of a building is part of its cultural heritage. With this in mind it has been highlighted that the building should only be moved for conservation as a last resort. Where this is done it is noted that the new site should provide a setting that is compatible with the heritage, conversely the heritage value of the building is not always extricably linked to its original location (Gregory, 2008). 


\section{Complete Building Translocation}

The complete relocation of a structure is not a new phenomenon and the first relocation of a complete building can be traced back to a building in London in 1598 (Drozd, 2019). It is often the case that the use of a complete building move is seen as the best option to retain all historic features of the building. When either partial or complete disassembly and reconstruction is used, it is inevitable that certain elements of the fabric will be lost either as part of the process or as collateral loss during the process (Jackier, 2001).

The movement of an entire structure can be a costly exercise, particularly when the distance required between the two sites is large. Very often, even if the distance is short it can be several days of slow movement to ensure stability of the structure (Huffman, 2007). As an example the Artuklu Hamam bathhouse in Turkey was relocated a distance of 3 kilometres using a purpose made vehicle (Bennett, 2019). In this case the building was cut from underneath the foundation in a complete structure but due to the complexity of the project, the translocation process cost approximately $\$ 7.1 \mathrm{~m}$. In addition to cost a further challenge relates to the actual excavation under the existing building without causing damage (Mcglashan, 2003). When undertaken as a temporary measure, for example as part of a wider construction process (Xu et al., 2014), or as a permanent move to protect from natural forces such as coastal erosion (Mcglashan, 2003) this adds additional complexity. One such example of this type of translocation is Belle Tout Lighthouse whereby the structure was lifted onto a constructed concrete beam system and moved 17 metres to a new 'safe' location (ICE, 2018). 
As the process of entire structure translocation has evolved, the technology which supports the move has developed to utilise the power of digital technologies. From its early methods of using horses to move the structure (Goblet, 2006), through to the use of computer-controlled jacks to lift the building structure, digital techniques are providing a more robust way to control the physical movement and lead to a more coordinated process. Furthering this move to the digital paradigm, some researchers are now investigating the potential of digital models to understand the structural implications of the move prior to any site works. Studies undertaken by Hong et al., (2010) and Ying et al., (2010) have implemented structural analysis software tools to simulate the movement of the structure and understand the forces imposed on the frame during the process. From this analysis, the most critical and dangerous aspects could be understood within a computer based 'safe' environment.

\section{Disassembly and Reconstruction Approaches}

When translocation by disassembly and reconstruction is implemented, the structure has to be disassembled into a number of discrete elements which requires a level of segmentation of the building components. The subdivision of the building into these individual elements is assessed as part of the translocation process and can be influenced by such factors as the structural integrity, the physical movement constraints or the architectural features. This disassembly form of translocation can be traced back as far as ancient Egypt and the Abu Simbel Temple where the structure was cut into pieces for transportation and reconstruction (Wong, 2016).

A constraining factor of this approach relates to the method of transportation, in addition to other factors such as maintaining the constructability (Drozd, 2019). 
Translocation using this approach can either be a full or partial disassembly of the structure. Where a partial disassembly is implemented, the building is subdivided into larger parts (Song et al., 2017) and each treated as a complete move. These segments can be identified according to the nature of the structure and any issues around the removal, such as transportation links. In the case of timber or masonry buildings the segments can be based on structural integrity (Garavaglia, 2006). In some cases this form of translocation is used to move the buildings a substantial distance from its initial location. In these cases, such as the Yin Yu Tang house which was moved from China to the USA to preserve heritage, architectural drawings, recorded on-site measurements and photographs were used to document the building which were then used in the reconstruction $(\mathrm{CNN}, 2017)$.

Even when the disassembly is undertaken and components are marked/numbered or tagged individually to identify specific pieces (along with photographs and drawings) (Gregory, 2008), these can number into the thousands and individual elements which can present challenges both in respect to management of documentation and also managing the physical elements which can be damaged or lost in transit (Huffman, 2007) . In addition, key measurements of the building whilst in its original location are required (Frazier Associates, 2005), to ensure these are maintained in the new location as an additional measure of accuracy and authenticity. A further example highlighted in (Goblet, 2006) follows a similar process of marking each component for identification to support the reconstruction but also discusses adequate and structured storage of the components and the creation of molds to replace those elements that could not be moved. The actual disassembly of the structure should include a systematic cataloguing approach, and this includes both the actual psychical parts of the structure and a method 
to identify where they are stored following removal from the structure. This could be enhanced through the use of digital drawings and simulations if possible (Tutkun, 2019).

During the disassembly, descriptions of specific architectural details such as decorative features should be logged, in addition where repetitive or symmetrical elements are used, these should have markers to identify the orientation of the piece is maintained in the new build (Jackier, 2001). Timber framed buildings are particularly suited for translocation due to a number of factors including the construction materials used and relatively low weight (Wesołowski, 2016). Work undertaken by (Smith et al., 2011) highlighted how the timber frame of a building could be relocated when a building is initially constructed with its potential demountabilty in mind from the outset.

The disassembly of the façade of the Boston Modern Theatre did begin to highlight the use of digital technologies to measure and record the profiles of each piece of stone which allowed the reconstruction to align with a new build (Gregorski, 2012). This example begins to show the potential of BIM technologies to support translocation work but more could be implemented to use the 'Information' aspect of BIM to log full details of the process and cataloguing of the translocation.

\section{Heritage BIM (HBIM)}

$\mathrm{BIM}$, as a paradigm, is focused on creating a database containing connected 3D geometric and informational data about objects (Eastman et al., 2011) This can then be used to support digitally enabled construction processes from inception through to asset management (Dakhil et al., 2019). Since it was first discussed by (Murphy et al., 2009), 
Heritage BIM (HBIM) has become a topic of great interest in recent years. This increase in the amount of research and application has mirrored the increase in the application BIM within the construction sector, both in respect to technology and process. (Dore \& Murphy, 2012) postulate that in addition to this, one of the main reasons for the increase is aligned to the more readily available access to laser scanning and photogrammetry, which are popular tools for recording the geometric properties of heritage buildings.

Volk et al., (2014) suggest that there are various methods for capturing survey data, which can subsequently be used in the development of a HBIM. Along with existing documentation, laser scanning and photogrammetry is very often seen as the starting point for HBIM, accurately capturing the buildings/sites physical and structural data (Khodeir et al., 2016). Such was the prevalence of laser scanning in the heritage domain that Historic England developed a formal document entitled '3D Laser Scanning for Heritage' covering issues surrounding available technologies and resolution (Historic England, 2018).

Following the capture of accurate measured data, the generation of the individual BIM follows a Scan-to-BIM or Scan2BIM methodology. This has been implemented in several studies on HBIM (Sánchez-Fernández et al., 2019; Rocha et al., 2020; Marzouk, 2020) whilst (Tang et al., 2010) summarise the Scan2BIM process in three distinct stages, comprising capture of point cloud data, processing of data to merge multiple and finally the geometric modelling using a BIM authoring tool. Previous efforts in the field of HBIM have sought to employ the modelling features of BIM tools through comprehensive parametric components (Apollonio et al., 2012) or construction method 
libraries (Fai \& Sydor 2013a). However, Logothetis et al., (2015) note that the nonstandard aspect of heritage architecture provides challenges surrounding the implementation of Heritage BIM as the built assets are comprised of components and materials whose geometry and characteristics are not representative for typical software libraries. A further issue within HBIM development is the Level of Detail of individual tangible elements, and to support this issue Historic England has defined four levels of graphical detail when generating 3D geometry in HBIM projects (Antonopoulou \& Bryan, 2017). The work undertaken by Mol et al., (2020) has highlighted the potential of HBIM to specifically facilitate a methodology to incorporate decay and damage information of timber structures. This approach used the HBIM model elements as a conduit to include measurement data from point clouds and image data of specific elements.

Garagnani (2015) emphasises the on-going need for HBIM and the ability to capture history and culture in a single repository, where all model elements, data and entities are integrated. A significant body of work focusing on the development of BIM for cultural heritage has focused on the development of the creation of tangible digital assets in the form of 3D geometric models (Fai \& Sydor, 2013b). Dore \& Murphy (2012) did propose that a 3D digital geometric model could contain historical information about the creation, origin and chronology of heritage objects. Fai et al. (2011) also suggested that HBIMs could contain non-graphical 'intangible' data such as photographs and oral histories. Taylor \& Counsell (2017) supported this view and in addition postulated the integration of additional tangible heritage data through use of sensors and recording of materials and this has potential to be aligned to some of the work proposed for entire building translocation to monitor movements during the process. 
As highlighted above, it has been noted that HBIM is most often referred to as the development of an individual digital model (or repository) containing geometric and other non-graphical information (Heesom et al., 2020). The process of Building Information Modelling is now well defined according to a range of standards including the ISO19650 documents (ISO, 2018) and defines the use of digital models and data to support the full range of the lifecycle of a built asset, from design through to operation (Winfield, 2020). In the case of translocation, the opportunity exists to utilise HBIM as a product but also draw upon prevailing BIM process to bring together the historic product (the building) and the translocation activities (process).

\section{HBIM for Translocation Framework (TransHBIM)}

Building on the above findings, Figure 3 presents the TransHBIM Conceptual Framework which develops relationships between salient aspects from expert knowledge derived from the practical relevance exercise and the technological and process potentials from BIM, and more specifically HBIM, workflows. The framework is specifically focused on translocation using a disassembly and reconstruction approach. 


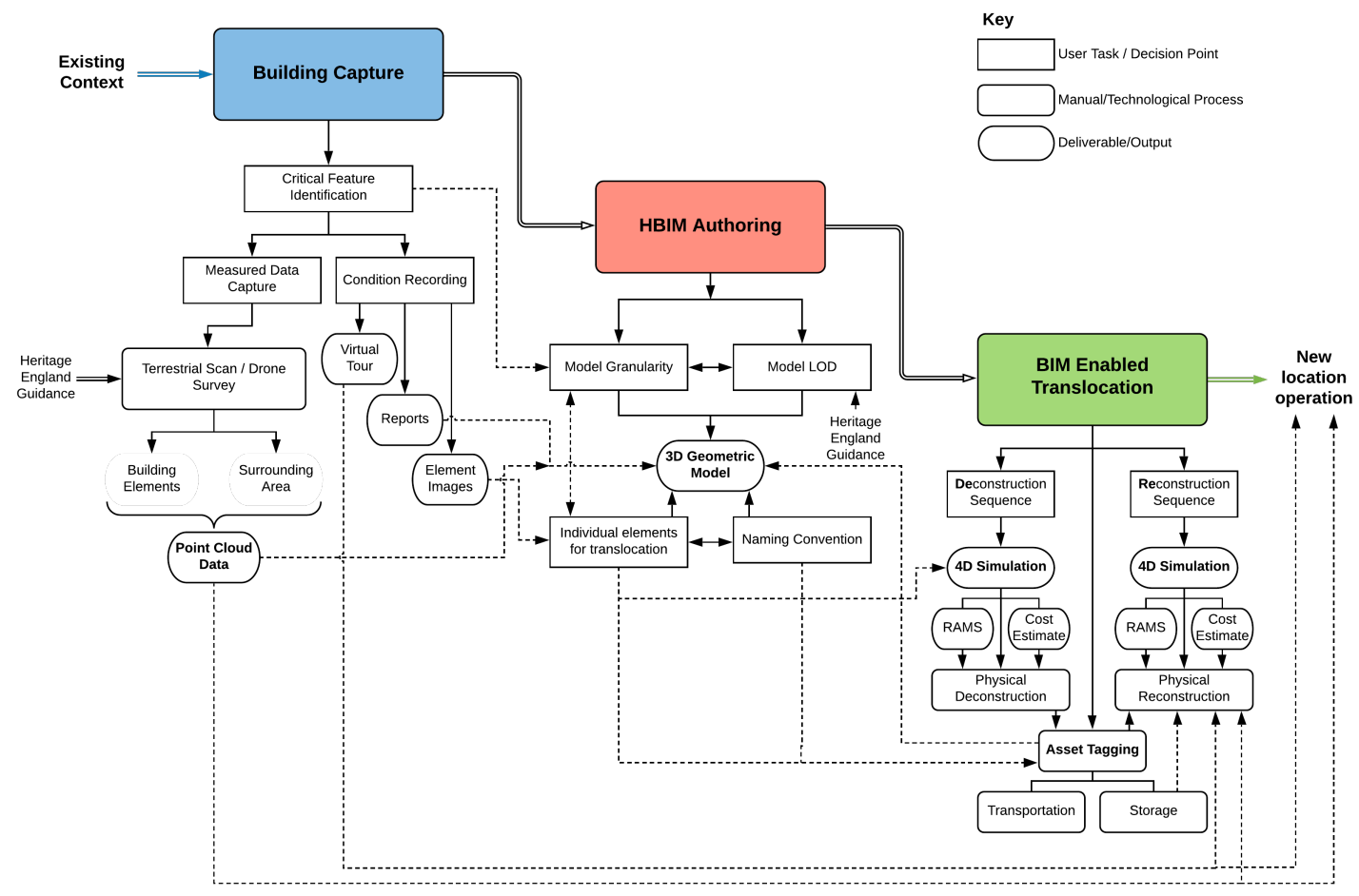

Figure 3: TransHBIM Conceptual Framework

The framework is divided into three primary constructs, namely building capture, HBIM authoring and BIM enabled translocation.

\section{Building Capture}

The first of these is focused on the capture of data using a fully digitally supported approach, enhancing the current methods of documenting the in-situ building. A core process underpinning this is the identification of critical features / elements to be translocated. Once these are identified then a number of digital survey approaches can be utilised and each of these integrated into the development of a HBIM. Terrestrial scan survey can be undertaken to accurately measure the building and, based on the specific elements to be translocated, the level of measurement detail can be adjusted to ensure adequate data is captured of relevant parts. The generation of this point cloud 
data can then be utilised later in the process during the reconstruction where a scan of the new reconstruction could be compared to the original through technology solutions such as Cloud Compare (Machete et al., 2020). This would allow quality assurance checks and identification of deviations in the new build. In addition to capturing the details of the building through terrestrial scanning, drone surveys and photogrammetry based approaches can be used generate point cloud data of the surrounding area to provide context. This data could be used to support the building within the new environment, as a previous criticism of translocation notes that historic buildings are sometimes relocated to a museum setting where they form part of a historic exhibit (Drozd, 2019) which is away from the original context. Using this original data along with the ability to use the BIM database to link intangible heritage data to provide detail of original genius loci. The development of virtual tours of the building can link with the HBIM dataset and also support the downstream reconstruction activities and the storage of digital reports and images can be fed into a BIM workflow and linked to the geometric model. These virtual tours can be generated from data captured from a laser scanner, by $360^{\circ}$ panoramic cameras or through use of dedicated photogrammetry hardware. The creation of these virtual tours allows a VR based walkthrough of the building in its original state and support geometric modelling but also support the construction team in understanding specific aspects during reassembly activities.

\section{HBIM Authoring}

Core to the development of the HBIM is identifying both the model granularity and the models geometric Level of Detail (LOD). The granularity focuses on the breakdown structure of individual elements to be translocated. For example, in a timber structure, if each piece is to be disassembled then the joints would need to be identified and each 
individual piece modelled such that it could be catalogued. The LOD refers to the amount of detail in the model of each individual element. In respect to BIM there are several definitions of LOD developed with have the underpinning philosophy of increasing the amount of geometric detail as the BIM model usage develops. BIMForum (2019) have developed a standard built on the AIA Contract Document G202-2013, whereas in the UK LOD is defined in the NBS Toolkit and is now integrated into the ISO19650 Level of Information Need (UK BIM Alliance, 2019). Specifically related to Heritage Buildings, and so adopted here, Historic England have defined four LOD which relate to the geometric modelling of existing historic buildings (Antonopoulou \& Bryan, 2017). It is also noted that these standards deal with establishing normalised practices for no geometric information through Level of Information (LOI), however at this time this has not been integrated into the framework due to the flexible nature of information required for translocation. This is an area of future development to standardise this information specifically in relation to translocation and conservation activities. The relationship between granularity and LOD is not linear - for example in the above scenario each of the elements could be modelled as simplistic geometry with a low LOD, but a high granularity. Also key to this aspect of the framework is naming convention used for each element of the model. Whilst a range of BIM based nomenclature exists such as Uniclass or Masterformat, specific naming processes can be specified on a project basis and will also feed into downstream activities during tagging elements of the build ready for disassembly, transportation and storage. 


\section{BIM enabled translocation}

The final construct relates to the use the digital data during both the physical disassembly and reconstruction of the building. Based on the model granularity and disassembly and reconstruction sequences, a 4D simulation can be developed to support the activities. This could then support the development of related Risk Assessments and Method Statement (RAMS) and align with prevailing approaches set out in standards such as PAS1192-6 (BSI, 2018). A critical aspect within this phase is the use of digital based tagging methods to generate a link between the HBIM geometric data, the captured survey and the condition recording. At this stage, the physical tagging of individual elements is based on the agreed granularity and naming convention. The use of an alpha numeric naming approach is implemented as this helps to ensure components are not only located in their original position but all correct orientation. The use of barcodes or active / passive Radio Frequency Identification (RFID) tags to implement this process will then create a 'digital bridge' between the physical elements of the building and the HBIM database. In addition, the use of tagging during the storage and transportation process will allow stakeholders to track and trace parts of the building.

\section{Framework Implementation}

In order to demonstrate the solution, the TransHBIM Framework was implemented on a disassembly-reconstruction project (Figure 4). The project involved the translocation of a timber framed cricket pavilion, originally constructed in 1876 . From a heritage perspective, the building was the original home of Worcester County Cricket Club in the UK and hosted the first Australian Touring side in 1878. Initially thatched; the roof covering was replaced with plain clay tiles in the early 20th century and the pavilion 
was extended slightly in two phases; in the late 19th Century and mid-20th Century. A comparative study indicates that the architectural design may have been inspired by the emerging Arts and Crafts movement which went on to influence the vernacular tradition of cricket pavilions into the 1920's (Lovejoy, 2006). The actual translocation process involved the main structural aspects of the building, the hardwood timber frame (including Arts and Crafts style cross-bracing), the roof trusses and all windows and doors.

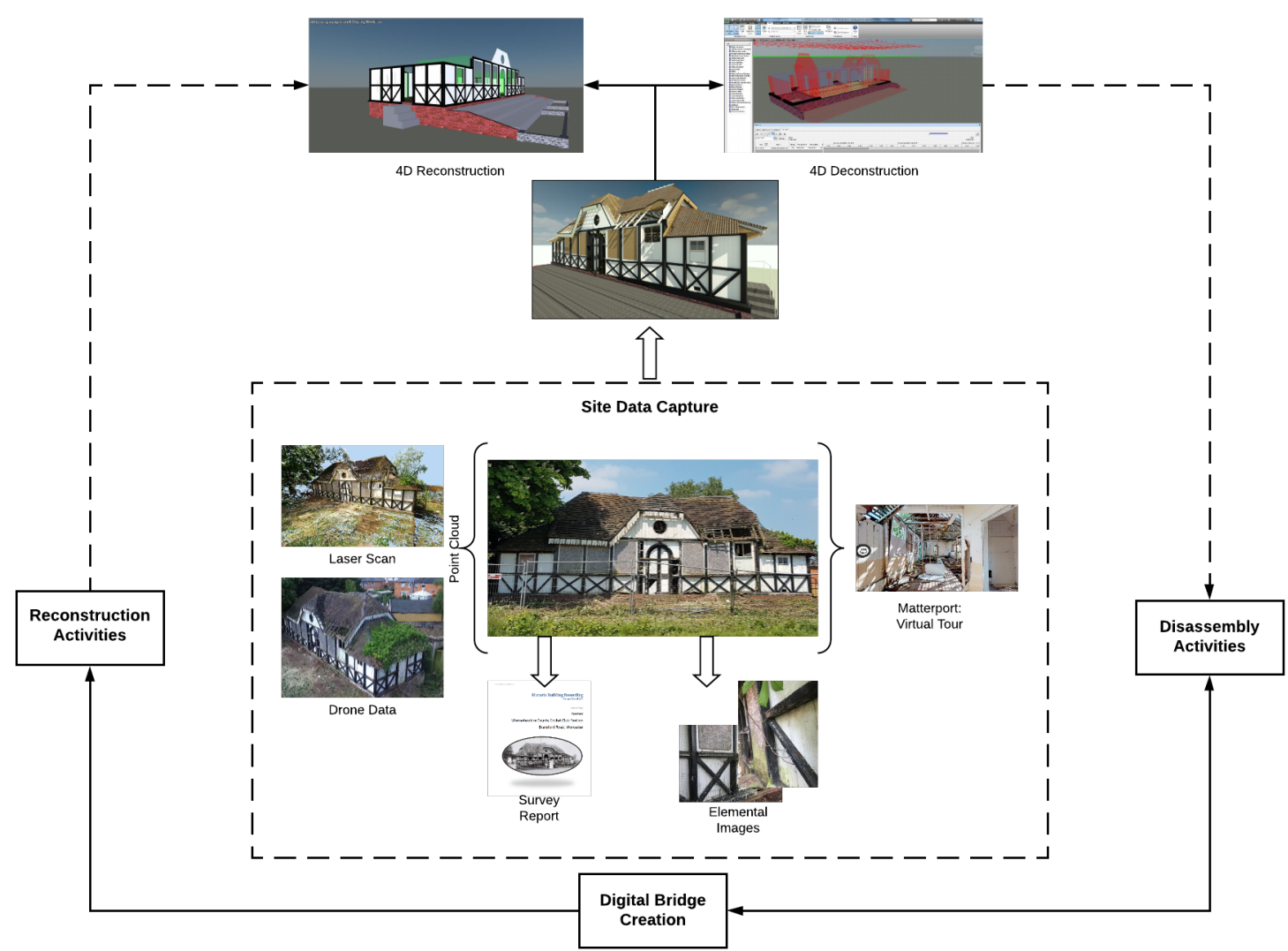

Figure 4: TransHBIM Project Implementation Workflow

Following the framework, the main features were identified for translocation activities and a terrestrial laser scan was undertaken of the internal and external features of the building. The complete scan used 22 individual scans from various locations using a Faro S150 scanner. The resolution was kept the same for all scans and an overall point 
cloud with a $5 \mathrm{~mm}$ point spacing was generated. In addition, a virtual tour of the building (pre disassembly) was undertaken using the Matterport system and this provided a visual inspection tool during the modelling process and also for later activities once relocated. The Matterport approach was taken for the virtual tour as it provided a high resolution, rapid, low cost web-based VR tour. In addition, the output also provided the ability to add 'hotspots' within the virtual tour which could link to photographs and any additional documents such as site sketches relating to the existing building.

The granularity was agreed with the conservation team and the building contractor responsible for the disassembly work, and this highlighted the need for each individual piece of structural timber to be modelled as a distinct entity. Following this, a complete 3D BIM was generated according to LOD3 of the Historic England guidelines as this provides an outline of the structure represented as solid objects and includes architectural features (Antonopoulou \& Bryan, 2017). The modelling of the building was undertaken within Autodesk Revit 2019 and utilised a Scan2BIM based approach to model the building as it currently existed. Due to the lack of standardised BIM object elements relating to this historic style (as noted above), many of the building elements were created using an in place model rather than an existing library. The naming convention for each HBIM object was based on Uniclass 2015 with each individual geometric element given a unique name based on a combination of Uniclass and the internal Revit unique ElementID. Once the model was complete a 4D deconstruction simulation was developed using Autodesk Navisworks to highlight the sequence of removal of the elements of the building. 
Based on the naming convention of the object, an individual barcode was generated for each piece of structural timber, truss, door and window. In this instance a barcode approach was chosen as it was lower cost to implement and had the ability to be implemented without the need for specialist RFID readers. This allowed data to be read and recorded via a smartphone app. Prior to disassembly each element of the building was tagged with a unique barcode that related back to that element in the HBIM to create the digital bridge (Figure 5).

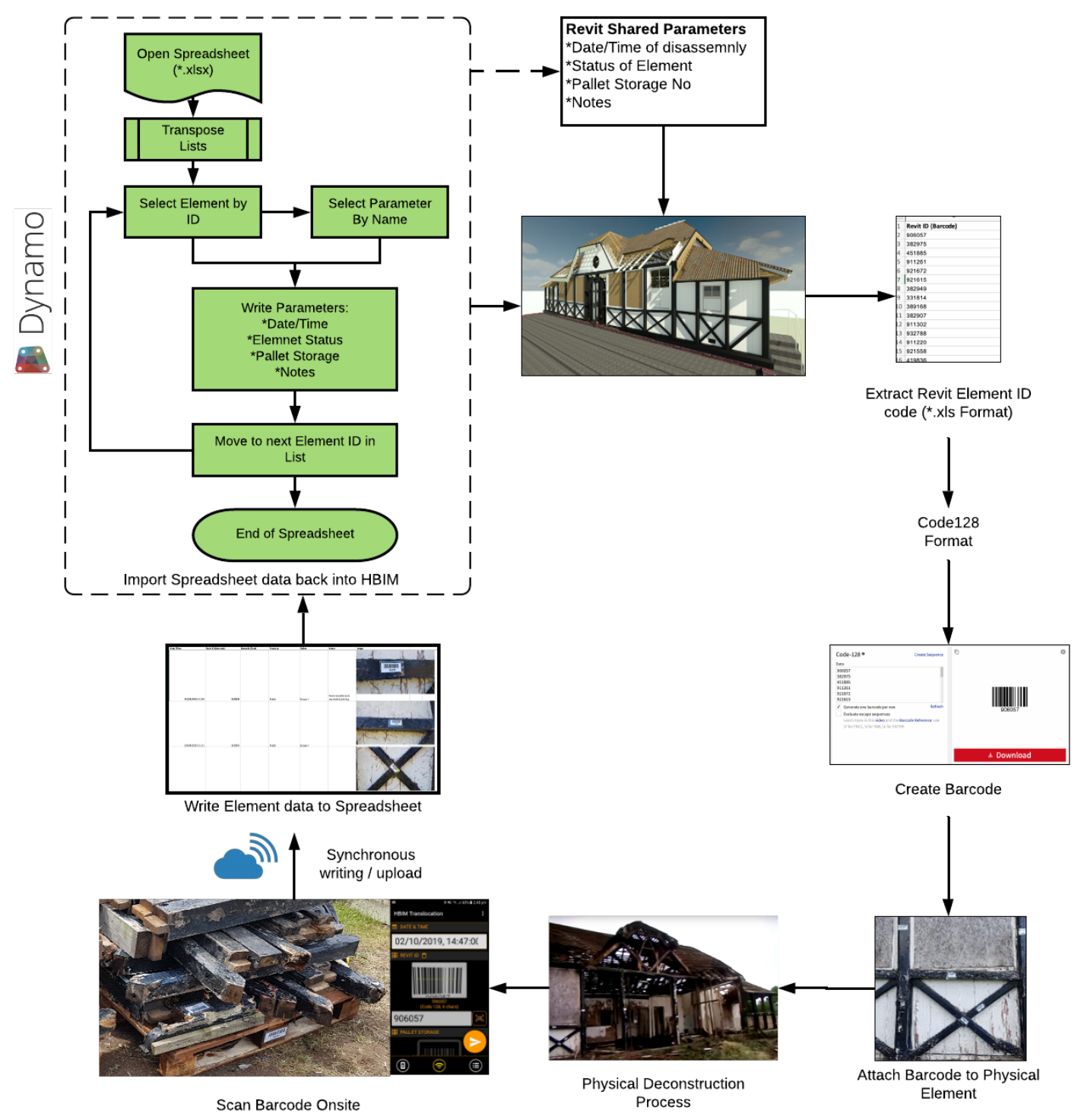

Figure 5: Workflow for implementing the Digital Bridge 
During the disassembly process, an Android app 'Scan-IT to Office' was employed to record each element as it was removed. The application provides the ability to capture a customised set of data from a barcode and instantly pushes this data to a cloud hosted spreadsheet (such as Excel 365 or Google Sheet). There are several Apps which currently allows barcode data to be captured and then pushed to a spreadsheet, however for this study the 'Scan-IT to Office' had some overriding benefits over similar apps. Firstly it allowed a specific translocation template to be developed within the app that allowed a range of data to be captured as the element was removed and this included, the date/time of removal, the unique ID of the element, data on whether the piece required any remedial work prior to reconstruction, the pallet number that the object was being stored on and a photograph showing the element 'in-situ' immediately prior to removal. Most other apps in this genre only allow barcode data to be captured and transmitted. Secondly this system allowed the data captured to be instantly linked to a cloud based spreadsheet by using the phone mobile data connection. This also provided the potential for the disassembly to be monitored and visualised remotely through the HBIM interface connected to the spreadsheet. This functionality enhances those of others in the marketplace as other require and offline transfer of data. Once completed a Dynamo script within Revit read the data from the spreadsheet and inserted this back into the properties of the Revit object through the implementation of shared parameters.

Subsequent to this, a 4D simulation was compiled of the reconstruction sequence using Autodesk Navisworks. Using the data contained in the BIM, the 4D simulation was able to support discussions around sequencing of the reconstruction but also highlight the storage location of each of the main structural elements and also identify which if any were in need of remedial work. 


\section{Conclusions}

This paper has reported on the implementation of HBIM technologies and processes to support the translocation of historic buildings. Specifically, this work sought to address the research gap which identified the lack of use of both BIM processes and technologies to support translocation. Hitherto, translocation using a disassembly and reconstruction based approach has been underpinned with traditional, manual processes including photographs, drawings and sketches with some advocating the use of laser scanning to record the building prior to work commencing. By formalising this process built on the philosophy of BIM, the work developed a framework and process of digital data capture and also advocated the use of multiple BIM technologies within this process which could be replicated on future translocation projects. Using a Constructive Research based approach, this work sought to formalise the knowledge of experts in this field and also draw on prevailing digital methods to generate the TransHBIM Framework which provides a roadmap for the use of BIM technologies and processes in the translocation of heritage buildings. Utilising the framework, an exemplar project involving the translocation of a $19^{\text {th }}$ Century timber framed building in the UK was undertaken. This demonstrated the integration of HBIM approaches such as laser scanning and 3D BIM creation with the use of 4D simulations and barcoding to create digital bridge and develop a synchronous link between on site disassembly activities and the HBIM dataset. The impact of this work on the translocation process leads to a more structured method of capturing initial building data but most importantly provides the ability to accurately record data about each element as it is being deconstructed in a real time situation. This then feeds into storage and transportation activities which ensures elements are correctly catalogued for the reassembly phase of the project which 
then saves time and money for the entire project. Underpinning all of this is the move towards using digital data throughout the entire process which transforms the traditional analogues approach to the translocation. This digital data then also allows disassembly and reconstruction to be simulated to ensure the most efficient process, thus saving time, cost and increasing safety aligning to the underlying philosophy of BIM in new or renovation construction. This process has the ability to be replicated on future translocation projects and can support all stakeholders in providing a more timely and cost efficient project.

It is noted that this particular study has focused on the translocation of a timber framed building which avails itself well to a full/partial deconstruction approach. However, other significant issues are presented when the translocation is related to a masonry building where the disassembly phase would be by individual brick. Further work will investigate how the framework and implementation can be adapted to suit this form of translocation with the option to subdivide and record walls into segments and record as a larger element. Further work is also proposed to develop the implementation of RFID tags to store further information as these hold the potential to store digital data within the tag and so could potentially be used both during the translocation but also store data which could be used, and updated, during the operation phase of the building post reassembly. Another avenue of investigation relates to the use of Augmented Reality (AR) to support the reconstruction activities by allowing the 4D reconstruction model to be overlaid onto the building to support the construction team. 


\section{Acknowledgements}

The authors are extremely grateful to the team at Avoncroft Museum of Historic

Buildings in the UK who have supported this work and allowed access to the case study project.

\section{References}

Antonopoulou, S. and Bryan, P. (2017), BIM for Heritage - Developing a Historic Building Information Model translated by Anonymous Historic England, Swindon, UK.

Apollonio, F.I., Gaiani, M. and Sun, Z. (2017), "A Reality Integrated BIM for Architectural Heritage Conservation", Handbook of Research on Emerging Technologies for Architectural and Archaeological Heritage IGI Global, pp. 31-65.

Apollonio, F.I., Gaiani, M. and Sun, Z. (2012), "BIM-based modeling and data enrichment of classical architectural buildings", SCIRES-IT: SCIentific RESearch and Information Technology, Vol. 2, No. 2, pp. 41-62.

Australia ICOMOS (2013), The Burra Charter, Australia ICOMOS charter for places of cultural significance, Available at: http://australia.icomos.org/wp-content/uploads/The-Burra-Charter-2013-Adopted31.10.2013.pdf (Accessed: 4 August 2020)

Baik, A., Yaagoubi, R. and Boehm, J. (2015), "Integration of Jeddah historical BIM and 3D GIS for documentation and restoration of historical monument", The International Archives of Photogrammetry, Remote Sensing and Spatial Information Sciences, Vol. 40, No. 5, pp. 29.

Barnes, P. (2019). BIM in Principle and in Practice. ICE Publishing.

Bennett, H. (2019), July 11,-last update, Monster movers: 6 massive machines for shifting rockets, turbines and even ancient buildings. Available:

https://www.sciencefocus.com/science/monster-movers-6-massive-machines-forshifting-rockets-turbines-and-even-ancient-buildings/ [2020, Apr 20,].

BIMForum (2020) Level of Development (LOD) Specification Part 1 and Commentary for Building Information Models and Data. Available at: https://bimforum.org/lod/ Accessed 4 August 2020

BSI (2018) Specification for collaborative sharing and use of structured Health and Safety information using BIM. British Standards Institute. 
CNN, A.L. (2017), -03-13T01:15:48Z-last update, Should China move its historic monuments?. Available: https:/www.cnn.com/style/article/china-movingmonuments/index.html [2019, May 27,].

Curtis, J.O. (1979), Moving historic buildings translated by Anonymous .

Dakhil, A.J., Underwood, J. and Alshawi, M. (2019), "Critical success competencies for the BIM implementation process: UK construction clients", Journal of Information Technology in Construction (ITcon), Vol. 24, pp. 80-94.

Dore, C., Murphy, M., McCarthy, S., Brechin, F., Casidy, C. and Dirix, E. (2015), "Structural simulations and conservation analysis-historic building information model (HBIM)", The International Archives of Photogrammetry, Remote Sensing and Spatial Information Sciences, Vol. 40, No. 5, pp. 351.

Dore, C. and Murphy, M. (2012), "Integration of Historic Building Information Modeling (HBIM) and 3D GIS for recording and managing cultural heritage sites", "Integration of Historic Building Information Modeling (HBIM) and 3D GIS for recording and managing cultural heritage sites", Virtual Systems and Multimedia (VSMM), 2012 18th International Conference on, IEEE, pp. 369.

Drozd, W. (2019), "Structure Relocation", Civil and Environmental Engineering Reports, Vol. 29, No. 4, pp. 176-184. available at: https://content.sciendo.com/view/journals/ceer/29/4/article-p176.xml.

Eastman, C.M., Eastman, C., Teicholz, P. and Sacks, R. (2011), BIM handbook: A guide to building information modeling for owners, managers, designers, engineers and contractors translated by Anonymous John Wiley \& Sons.

Etikan, I., Musa, S.A. and Alkassim, R.S. (2016), "Comparison of convenience sampling and purposive sampling", American journal of theoretical and applied statistics, Vol. 5, No. 1, pp. 1-4.

Fai, S., Graham, K., Duckworth, T., Wood, N. and Attar, R. (2011), "Building information modelling and heritage documentation", "Building information modelling and heritage documentation", Proceedings of the 23rd International Symposium, International Scientific Committee for Documentation of Cultural Heritage (CIPA), Prague, Czech Republic, pp. 12.

Fai, S. and Sydor, M. (2013a), "Building Information Modelling and the documentation of architectural heritage: Between the 'typical'and the 'specific'", "Building Information Modelling and the documentation of architectural heritage: Between the 'typical'and the 'specific'", Digital Heritage International Congress (DigitalHeritage), 2013, IEEE, pp. 731.

Fai, S. and Sydor, M. (2013b), "Building Information Modelling and the documentation of architectural heritage: Between the 'typical'and the 'specific'", "Building Information Modelling and the documentation of architectural heritage: Between the 'typical'and the 'specific'", Digital Heritage International Congress (DigitalHeritage), 2013, IEEE, pp. 731. 
Garagnani, S. (2015), "Semantic representation of accurate surveys for the cultural heritage: BIM applied to the existing domain", Handbook of Research on Emerging Digital Tools for Architectural Surveying, Modeling, and Representation, Vol. 1, pp. 299-317.

Garavaglia, M. (2006), "Doyle Drive Relocation - Building Relocation Feasibility Study", Commercial, .

Goblet, N. (2006), "Moving Historic Buildings: One Means of Preservation".

Gregorski, T. (2012), "28th Annual Reconstruction Awards: Modern day reconstruction plays out", Building Design \& Construction, .

Gregory, J. (2008), "Reconsidering relocated buildings: ICOMOS, authenticity and mass relocation", International Journal of Heritage Studies, Vol. 14, No. 2, pp. 112-130.

Guo, T., Li, A., Wei, L. and Gu, Y. (2013), "Horizontal translocation of a high-rise building: Case study", Journal of Performance of Constructed Facilities, Vol. 27, No. 3, pp. 235-243.

Heesom, D., Boden, P., Hatfield, A., Rooble, S., Andrews, K. and Berwari, H. (2020), "Developing a collaborative HBIM to integrate tangible and intangible cultural heritage", International Journal of Building Pathology and Adaptation, .

Historic, E. (2018), 3D Laser Scanning for Heritage: Advice and Guidance on the Use of Laser Scanning in Archaeology and Architecture, 2nd ed., translated by Anonymous Historic England, Swindon, UK.

Huffman, A. (2007), Take It Away.

ICE (2018), 15/10/ 12:00:00-last update, Moving the Belle Tout Lighthouse. Available: https://www.ice.org.uk/what-is-civil-engineering/what-do-civil-engineersdo/moving-the-belle-tout-lighthouse [2019, Jun 6,].

J. Xu, Y. Chen, T. Guo and Z. Di (2014), Protection of Historic Buildings through Structural Translocation during Construction of Deep Foundation Pit.

Jackier, D.A. (2001), "Moving Historic Structures: The Washington Street Urban Renewal Project".

Kasanen, E., Lukka, K. and Siitonen, A. (1993), "The constructive approach in management accounting research", Journal of management accounting research, Vol. 5, No. 1, pp. 243-264.

Khodeir, L.M., Aly, D. and Tarek, S. (2016), "Integrating HBIM (Heritage Building Information Modeling) tools in the application of sustainable retrofitting of heritage buildings in Egypt", Procedia Environmental Sciences, Vol. 34, pp. 258270. 
Kolakowski, T. (2015), "Translocation of Historic Monuments as an Economic Project", Journal of Interdisciplinary Research, Vol. 5, No. 2, pp. 31-35.

Laing, R., Leon, M., Isaacs, J. and Georgiev, D. (2015), "Scan to BIM: the development of a clear workflow for the incorporation of point clouds within a BIM environment", WIT Transactions on The Built Environment, Vol. 149, pp. 279-289.

Lehtiranta, L., Junnonen, J., Kärnä, S. and Pekuri, L. (2015), "The Constructive Approach: Problem Solving for Complex Projects", in B. Basian(Ed.), Designs, Methods and Practices for Research of Project Management Gower Applied Business Research, UK, pp. 95-106.

Logothetis, S., Delinasiou, A. and Stylianidis, E. (2015), "Building information modelling for cultural heritage: a review", ISPRS Annals of the Photogrammetry, Remote Sensing and Spatial Information Sciences, Vol. 2, No. 5, pp. 177.

Lu, W. and Wang, Y. (2016), "Performance-Based Design Method for Key Techniques in Construction Management of Buildings Translocation Project in China".

Lukka, K. (2003), "The Constructive Research Approach", in L. Ojala \& O. Hilmola(Eds.), Case study research in logistics Turku School of Economics and Business Administration, Turku, Finland, pp. 83-101.

Machete, R., Falcão, A.P., Gonçalves, A.B., Godinho, M. and Bento, R. (2020), "Development of a Manueline Style Object Library for Heritage BIM", International Journal of Architectural Heritage, , pp. 1-12.

Marzouk, M. (2020), "Using 3D laser scanning to analyze heritage structures: the case study of Egyptian Palace", Journal of Civil Engineering and Management, Vol. 26, No. 1, pp. 53-65.

Mcglashan, D.J. (2003), "Managed relocation: an assessment of its feasibility as a coastal management option", The Geographical Journal, Vol. 169, No. 1, pp. 6-20. available at: https://doi.org/10.1111/1475-4959.04993.

Mol, A., Cabaleiro, M., Sousa, H.S. and Branco, J.M. (2020), "HBIM for storing lifecycle data regarding decay and damage in existing timber structures", Automation in Construction, Vol. 117, pp. 103262.

Mordue, S., Swaddle, P. and Philp, D. (2015), Building information modeling for dummies translated by Anonymous John Wiley \& Sons.

Murphy, M., McGovern, E. and Pavia, S. (2009), "Historic building information modelling (HBIM)", Structural Survey, Vol. 27, No. 4, pp. 311-327.

Oyegoke, A. (2011), "The constructive research approach in project management research", International Journal of Managing Projects in Business, Vol. 4, No. 4, pp. 573-595. 
Peltola, X.C. (2008), Moving historic buildings: A study of what makes good preservation practices when dealing with historically significant buildings and structures, ProQuest Dissertations Publishing.

Podhalański, B. and Połtowicz, A. (2019), "Regeneration of a historic city block: the example of the relocation of the historic Atelier building to the cloister area of the Congregation of the Resurrection in Krakow", Urban Development Issues, Vol. 63, No. 1, pp. 77-86.

Riaz, Z., Parn, E.A., Edwards, D.J., Arslan, M., Shen, C. and Pena-Mora, F. (2017), "BIM and sensor-based data management system for construction safety monitoring", Journal of Engineering, Design and Technology, Vol. 15, No. 6, pp. 738-753.

Rocha, G., Mateus, L., Fernández, J. and Ferreira, V. (2020), "A scan-to-BIM methodology applied to heritage buildings", Heritage, Vol. 3, No. 1, pp. 47-67.

Sánchez-Fernández, M., Chorro, F.J., Marín, M., de Sanjosé-Blasco, J.J. and Martínez, L.F. (2019), "Data Management in "Scan to HBIM" Projects", "Data Management in "Scan to HBIM" Projects", International conference on The Digital Transformation in the Graphic Engineering, Springer, pp. 527.

Saunders, M., Lewis, P. and Thornhill, A. (2016), Research methods for business students translated by Anonymous Pearson Education, New York.

Schweber, L. (2015), "Putting theory to work: the use of theory in construction research", Construction Management and Economics, Vol. 33, No. 10, pp. 840860 .

Smith, T., Wong, R., Newcombe, M., Carradine, D., Pampanin, S., Buchanan, A., Seville, R. and McGregor, E. (2011), "The demountability, relocation and re-use of a high performance timber building".

Song, Y., Guo, T., Di, Z., Wei, L. and Wei, H. (2017), "Translocation of Three Historical Buildings in Renovation of the Porcelain Tower of Nanjing", Journal of Performance of Constructed Facilities, Vol. 32, No. 1, pp. 04017125.

Succar, B. (2009), "Building information modelling framework: A research and delivery foundation for industry stakeholders", Automation in Construction, Vol. 18, No. 3, pp. 357-375.

Tang, P., Huber, D., Akinci, B., Lipman, R. and Lytle, A. (2010), "Automatic reconstruction of as-built building information models from laser-scanned point clouds: A review of related techniques", Automation in Construction, Vol. 19, No. 7, pp. 829-843.

Taylor, T. and Counsell, J. (2017), "What are the goals of HBIM?", Heritage Building Information Modelling Routledge, pp. 15-31. 
Tomaszek, T. (2020), Authenticity in the Preservation of Historical Wooden Architecture-Problems and Challenges: Case Studies from the American South translated by Anonymous CRC Press.

Tommasi, C., Achille, C. and Fassi, F. (2016), "From Point Cloud to Bim: a Modelling Challenge in the Cultural Heritage Field", ISPRS - International Archives of the Photogrammetry, Remote Sensing and Spatial Information Sciences, , pp. 429-436. available at: http://adsabs.harvard.edu/abs/2016ISPAr41B5..429T.

Tutkun, M. (April 2019), "A GUIDE PROPOSAL FOR RELOCATION PRACTICES IN CONSERVATION OF ARCHITECTURAL HERITAGE", "A GUIDE PROPOSAL FOR RELOCATION PRACTICES IN CONSERVATION OF ARCHITECTURAL HERITAGE", International Civil Engineering and Architecture Conference 2019, Karadeniz Technical University, Trabzon, Turkeu, 17-20 April 2019, pp. 802.

UK BIM Alliance (2019) Information Management according to BS EN ISO 19650. Available at: https://www.ukbimalliance.org/wpcontent/uploads/2019/03/Information-Management-according-to-BS-EN-ISO19650-Guidance-Part-1-Concepts-1.pdf Accessed 4 August 2020

Volk, R., Stengel, J. and Schultmann, F. (2014), "Building Information Modeling (BIM) for existing buildings-Literature review and future needs", Automation in Construction, Vol. 38, pp. 109-127.

Wesołowski, $€$ (2016), "Relocation of buildings - rationale and implementation potential", Wiadomości Konserwatorskie (Journal of Heritage Conservation), Vol. 47, pp. 40-51. available at:

http://yadda.icm.edu.pl/baztech/element/bwmeta1.element.baztech-558ca7a4-da1d4b09-834d-a5d163a9a1a9/c/WesolowskiL_TranslokacjaObiektow.pdf.

Winfield, M. (2020), "Construction 4.0 and ISO19650: A Panacea for the Digital Revolution?", Proceedings of the Institution of Civil Engineers-Management, Procurement and Law, , pp. 1-6.

Wong, L. (2016), Adaptive Reuse: Extending the Lives of Buildings, 1st ed., translated by Anonymous Birkhauser.

Xu, J., Chen, Y., Guo, T. and Di, Z. (2014), "Protection of Historic Buildings through Structural Translocation during Construction of Deep Foundation Pit", "Protection of Historic Buildings through Structural Translocation during Construction of Deep Foundation Pit", , IEEE, pp. 964.

Y. Hong, H. Jin and R. Yang (2010), The Analysis of Frame Structure Building Monolithic Movement with ANSYS.

Ying Hong, Ruijun Yang and Hailu Jin (2010), The force analysis of frame structure building relocation based on ANSYS. 
Yusran, Y.A., Mahendar Bagaskara, Y.V. and Santoso, J.T. (2019), "Exploring Joglo's Translocation as an Effort in Conserving Indonesian Vernacular Architecture (Case Study of Griya Joglo in Kampoeng Djawi)", IOP Conference Series: Earth and Environmental Science, Vol. 239, pp. 012048. available at: http://dx.doi.org/10.1088/1755-1315/239/1/012048.

Zhang, R., Xue, S., Xie, L., Zhang, F. and Lu, W. (2019), "Structural Monitoring and Safety Assessment during Translocation of Mahavira Hall of Jade Buddha Temple", Sustainability, Vol. 11, No. 19, pp. 5477. 